\section{Los observadores de la Iglesia Ortodoxa Rusa al Concilio Vaticano II*}

\author{
Gonzalo Arias Cárdenas ${ }^{a}$ \\ Pontificio Instituto Oriental, Roma \\ Arquidiócesis de Bogotá, Colombia \\ https://orcid.org/0000-0002-7470-8752
}

RECIBIDO: 24-10-18. APROBADO: 05-02-19

Resumen: El artículo trata sobre la participación de los observadores del Patriarcado de Moscú al Concilio Vaticano II. Su presencia -al lado de representantes de otras iglesias no en plena comunión con la Iglesia de Roma- fue determinante para que se llevara a cabo "el gran examen de conciencia de la Iglesia" en referencia al problema del restablecimiento de la unión de todos los cristianos. En una sede de tal magnitud como la de un Concilio ecuménico de la Iglesia Católica, se tomó contacto y conciencia de esta realidad y de la necesidad imperiosa de dar inicio a un diálogo constructivo que sentara bases sólidas para volver a la unidad deseada y orada por Cristo antes de su inmolación en la cruz. Se puede apreciar de manera sintética el camino seguido por católicos y ortodoxos, los pasos dados y el crecimiento que se dio antes, durante y después del inmediato posconcilio.

Palabras clave: Iglesia Ortodoxa Rusa; Patriarcado de Moscú; diálogo ecuménico; observadores; Unión de los Cristianos; Concilio Vaticano II.
Observers of the Russian Orthodox Church to the Second Vatican Council

Авstract: The article deals with the participation of the Observers of the Patriarchate of Moscow at the Second Vatican Council. Their presence, with that of the representatives of other churches not in full communion with the Church of Rome, was decisive to carry out the "great examination of conscience" of the Church regarding the restoration of the union among all Christians. In an event of such magnitude as the Ecumenical Council of the Catholic Church, awareness of that reality was raised, as well as the imperative need to start a constructive dialogue with solid foundations to return to the unity desired and prayed by Christ before his immolation on the cross. It will be possible to appreciate-in a synthetic way - the path followed by Catholics and Orthodox, the steps taken and the growth that occurred before, during and after the immediate post Council.

Key Words: Russian Orthodox Church; Patriarchy of Moscow; Ecumenical Dialogue; Observers; Christians Union; Second Vatican Council.

\section{CÓMO CITAR:}

Arias Cárdenas, Gonzalo. "Los observadores de la Iglesia Ortodoxa Rusa al Concilio Vaticano II". Theologica Xaveriana (2020): 1-26. https://doi.org/10.11144/javeriana. tx70.oiorcv

*Artículo de investigación

${ }^{a}$ Autor de correspondencia. Correo electrónico: frgonzo23@hotmail.com 


\section{Introducción}

El Concilio Vaticano II fue un acontecimiento eclesial que en el ámbito ecuménico dio un giro trascendental en las relaciones de la Iglesia Católica romana con las demás iglesias cristianas de Oriente y de Occidente. Con las comunidades orientales se dejaban atrás casi mil años de indiferencia, y con las occidentales, casi medio milenio de polémicas y acusaciones.

En su momento, la presencia de representantes del Patriarcado de Moscú como observadores delegados de esta Iglesia Ortodoxa al Concilio fue algo sorprendente. El hecho motivó un interés especial por parte del mismo evento conciliar y de los medios de comunicación del mundo, ya que la geopolítica y la mentalidad de entonces veían este acontecimiento como algo insólito, llamativo, e incluso para algunos, preocupante.

El Concilio permitió un encuentro entre cristianos de todas las denominaciones que difícilmente se hubiera podido realizar en otros escenarios, aunque el Consejo Ecuménico de las Iglesias había dado pasos interesantes en este sentido con reuniones que convocaban a representantes de muchas iglesias, pero de duración limitada a días o semanas. En cambio, el Vaticano II permitió que tales contactos se prolongasen por cuatro años, es decir, durante el tiempo que duró el Concilio. Esto hizo madurar a la Iglesia toda acerca del problema lacerante de las divisiones entre aquellos que se llaman cristianos.

La invitación a los otros cristianos a participar de alguna manera en el Concilio y su aceptación dio inicio a una serie de relaciones, conocimientos, encuentros y experiencias nuevas que ayudaron a desintoxicar las relaciones y ver aspectos nuevos y desconocidos en el otro; y al finalizar el Vaticano II se habría de advertir cuán positiva resultó la experiencia de hacer este camino juntos, Oriente y Occidente.

\section{Reacciones ante la convocación del Concilio}

En un primer momento, todas las iglesias ortodoxas creyeron que el papa Juan XXIII deseaba convocar un Concilio ${ }^{1}$ que fuese ante todo un Concilio de unión-como los de Lyon o Florencia-, en el cual los cristianos de cada confesión y de cualquier tendencia habrían tenido el derecho a participar²; pero después el mismo Papa aclaró las cosas,

\footnotetext{
${ }^{1}$ El Concilio Vaticano II fue convocado por el papa Juan XXIII, el lunes 25 de diciembre de 1961, mediante la constitución apostólica Humanae salutis.

2 "La primera impresión en los ambientes ortodoxos fue, pues, más allá de sorpresa, de temor. Se creyó en efecto que el Papa tuviese la intensión de convocar un Concilio unionista, a la manera del Concilio de Florencia (1439), y de frente a esta posibilidad se manifestó inmediatamente la poca preparación doctrinal y organizativa de las comunidades ortodoxas, más aún, la peligrosidad para ellas de tal evento:
} 
haciendo entender que si bien el Concilio solo había convocado para sus trabajos a los obispos en plena comunión con la Iglesia de Roma, también había asumido una dimensión ecuménica en cuanto uno de sus más altos objetivos era la apertura de una vía y un diálogo fraterno con los "hermanos separados".

La primera actitud del Patriarcado de Moscú al conocer el anuncio hecho por el Papa sobre el futuro Concilio fue el de un profundo silencio. Solo algunos meses más tarde, el patriarca Alexis I ${ }^{3}$ hizo una declaración, el 21 junio 1959, en Izvestia ${ }^{4}$ y en el número de julio del mismo año de la Revista del Patriarcado de Moscú: "El Patriarcado de Moscú considera el Concilio católico como un asunto interno de la Iglesia romana. El Patriarcado no tiene ninguna razón ni intención de inmiscuirse en ese asunto"s.

Si bien la Iglesia rusa siguió con cierto interés y reserva la preparación del Concilio, más adelante, cuando se oyó hablar sobre la posibilidad de enviar observadores, el Patriarcado ruso se pronunció mediante un artículo anónimo publicado en mayo de 1961, en la Revista del Patriarcado de Moscú, bajo el título "Non possumus", en el cual especificaba las razones por las cuales era imposible participar al Concilio ${ }^{6}$.

Por su parte, Nikodim 7 , arzobispo de Yaroslav y Rostov, y responsable del Departamento para los Asuntos Exteriores del Patriarcado de Moscú, durante la Conferencia

esto podía resultar en una grave crisis religiosa, que habría difundido más ampliamente el escepticismo y el indiferentismo religioso y habría profundizado aún más las divergencias y divisiones internas en la ortodoxia moderna" (Caprile, Il Concilio Vaticano II. Cronache del Concilio Vaticano II, Vol. I. L'annunzio e la prepazione, 1959-1962: Parte 1. 1959-1960, 383).

${ }^{3}$ Alexis I (Serguéi Vladimírovich Simanski). 9 de noviembre de 1877-17 de abril de1970. Fue Patriarca de Moscú y de toda Rusia de 1945 a 1970. Después de haber completado estudios, primero jurídicos y después teológicos, se hizo monje en 1902, sacerdote en 1903 y finalmente, en 1913, obispo de Tikhvin. Se convirtió en jefe espiritual de la diócesis de Nóvgorod en 1926, metropolita de Leningrado en 1933 y Patriarca en 1945. En 1943 discutió con Stalin la posibilidad de un modus vivendi entre Iglesia y Estado. Después de largas negociaciones, en 1961, la Iglesia Ortodoxa Rusa entró a formar parte del Consejo Ecuménico de las Iglesias (CEI) (N. Lossky; G. Cereti; A. Filippi; y L. Sartori, eds., Dizionario del movimento ecumenico [Bologna: Edizioni Dehoniane Bologna, 1994], 14).

${ }^{4}$ Diario de alta circulación en Rusia desde los tiempos de la Unión Soviética. Fue fundado el 17 de marzo de 1917 y durante el periodo soviético expresó la opinión oficial del gobierno publicada por el Presidium del Sóviet Supremo de la URSS.

${ }^{5}$ Wenger, Le Concile Vatican II. Croniques des sessions du Concile. Vol. I. Cronique de la Ire session, 204. ${ }^{6}$ Ibíd., 207-209.

${ }^{7}$ Nikodim (Boris Yeoryévich Rotóv). Frolovo (URSS), 14 de octubre de 1929-Roma, 5 de septiembre de 1978. A él se debe la entrada del Patriarcado de Moscú al Consejo Ecuménico de las Iglesias en 1961. Fue miembro de las comisiones central y ejecutiva del Consejo Ecuménico de las Iglesias y fue después su presidente, en 1975. Fue responsable del Departamento para los Asuntos Exteriores del Patriarcado de Moscú por doce años (1960-1972). Fue arzobispo de Yaroslav, en 1961, y metropolita de Minsk y de Leningrado en 1963. Trabajó fervientemente por el mejoramiento de las relaciones con la Iglesia Católica romana y fue un gran admirador del papa Juan XXIII. Nikodim murió durante una audiencia 
Pancristiana de la Paz a Praga, en junio de 1961, se expresó de la siguiente manera acerca del Concilio y de la Iglesia Católica:

Es desagradable la ausencia de los católicos a este Congreso. Ella expresa, por parte de los jefes de la Iglesia Católica, una falta de amor por la paz. El dogma del primado del Papa ha aislado a la Iglesia Católica de las otras iglesias. Ella busca salir hoy de este aislamiento por medio del Concilio y se sostienen conversaciones con representantes de las otras iglesias. Pero es fácil comprender que el objetivo del Concilio no consiste en unir a los cristianos, sino dividirlos según los criterios políticos que fueron y permanecen inmutables para el Vaticano. ${ }^{8}$

...la teoría del Papa es la expresión más sintética y clara del espíritu de mundanidad y de legalismo externo que ha penetrado, en notable medida, en la vida y en la enseñanza de la Iglesia Católica [...]. No es solo casualidad que el abismo entre el Vaticano y la humanidad progresista se acreciente cada día que pasa; nosotros pensamos que un conflicto entre las masas de los católicos creyentes, por un lado, y los jerarcas del Vaticano, por otro, es inevitable. Este conflicto del resto ya ha iniciado con la liquidación de uniones como la de Brest $^{9}$, tan importante para el Vaticano como cabeza de puente para poder penetrar en Oriente. ${ }^{10}$

En el mismo año, en entrevista con el padre Antoine Wenger, de La croix, el metropolita Nikodim afirmó:

Se escribe siempre en la prensa que la Iglesia Ortodoxa Rusa tiene sentimientos poco amigables hacia la Iglesia romana. Debo decir que estas afirmaciones no se corresponden con la realidad. Los cristianos ortodoxos rusos albergan los mejores sentimientos fraternos hacia la Iglesia Católica toda, hacia su jerarquía y sus fieles. Pero la Iglesia rusa no aprueba la actividad que el Vaticano muestra en el campo político. En sus relaciones, el Vaticano se muestra a menudo opuesto a nuestro país. Nosotros, fieles de la Iglesia Ortodoxa Rusa, somos también ciudadanos leales de nuestro país y amamos ardientemente nuestra patria. Por esto, toda expresión dirigida contra nuestro país no contribuye a

con Juan Pablo I. Intrépido frente a los frecuentes y duros ataques contra su nación, su Iglesia y su misma persona, Nikodim fue un abierto defensor del Consejo Ecuménico de las Iglesias y un incansable promotor de la unidad de las iglesias. (N. Lossky; G. Cereti; A. Filippi; y L. Sartori, eds., Dizionario del movimento ecumenico [Bologna: Edizioni Dehoniane Bologna, 1994], 776-777).

${ }^{8}$ Wenger, Le Concile Vatican II. Croniques des sessions du Concile. Vol. I. Cronique de la Ire session, 206.

${ }^{9}$ Se denomina Unión de Brest a la decisión adoptada en 1596 por la Metropolía de Kiev, Galitzia y toda Rus de la Iglesia Ortodoxa de romper su dependencia del Patriarca de Constantinopla y entrar en comunión con la Iglesia Católica bajo la autoridad del Papa de Roma, a fin de evitar la dominación por el recién creado Patriarcado de Moscú, en 1589. La unión se formalizó en la ciudad de Brest, en la República de las Dos Naciones (o Comunidad Polaco-lituana), en la moderna Bielorrusia. El grupo resultante es la actual Iglesia Greco-Católica Ucraniana.

${ }^{10}$ Floridi, Mosca e il Vaticano, 130. [Traducción del autor]. 
mejorar nuestras relaciones mutuas. Nosotros no aprobamos estas actividades políticas de la Iglesia Católica romana y las condenamos. Sin embargo, nosotros no estamos contra la Iglesia Católica como tal. ${ }^{11}$

Estas actitudes y comentarios reflejaban, en su momento, hostilidad y prevención por parte de la Iglesia Ortodoxa Rusa ante el acontecimiento del Concilio de la Iglesia Católica. Al no tener más que informaciones parciales y fragmentadas, sus primeras posiciones fueron de defensa prevenida y de máxima atención ante los movimientos que realizaban los católicos en este campo.

A eso hay que sumar, además, nueve siglos de incomprensiones y desconocimiento entre estas iglesias, la asunción de posiciones y concepciones en extremo politizadas y la ausencia casi absoluta de cualquier tipo de contacto entre dos mundos que se sentían de por sí antagonistas. No obstante, durante las fases antepreparatoria y preparatoria del Concilio, la Iglesia Ortodoxa Rusa -y con ella las otras iglesias ortodoxas- tuvieron la posibilidad de comprender mejor el objetivo del Concilio y la evolución que, en diversos aspectos, se había puesto en marcha al interior de la Iglesia Católica, de tal manera que esta actitud habría de transformarse en un interés genuino por los trabajos preparatorios del Concilio.

\section{La invitación a participar del Concilio}

\section{Algunos antecedentes}

¿Cómo se llegó a invitar a observadores no católicos al Concilio Vaticano II? Sobre esta idea había ya algunas propuestas en el momento en que el papa Pío XI consultó al episcopado sobre una eventual reanudación del Concilio Vaticano ${ }^{12}$. Otros precedentes históricos más remotos se encuentran en la invitación dirigida a los representantes de confesiones no católicas para participar al Concilio de Trento.

L'Osservatore Romano del 22 de marzo de 1962 publicó un artículo titulado "Los acatólicos al Concilio de Trento", que habla sobre las negociaciones adelantadas por la Santa Sede, en particular con los protestantes, para proveerles de un salvoconducto especial que garantizara que pudieran llegar incólumes al Concilio tridentino ${ }^{13}$.

${ }^{11}$ Wenger, Le Concile Vatican II. Croniques des sessions du Concile. Vol. I. Cronique de la Ire session, 211-212. [Traducción del autor].

${ }^{12}$ Caprile, Il Concilio Vaticano II. Cronache del Concilio Vaticano II, Vol. I. L'annunzio e la prepazione, 1959-1962: Parte 1. 1959-1960, 12.13.

${ }^{13}$ Callovini, "Gli acattolici al Concilio di Trento", 6. 
De las invitaciones hechas a los no católicos para participar en Trento, es interesante subrayar la del papa Pío IV al zar Iván IV de Rusia, para que hiciera presencia en el Concilio mediante el envío de representantes de la Iglesia Ortodoxa Rusa. Infortunadamente, la oposición de los reyes de Polonia de ese entonces impidió que los mensajeros del Papa llegaran con su invitación a Moscú, y el Pontífice vio frustrada así su iniciativa de procurar la presencia de los rusos al Concilio ${ }^{14}$. El diálogo, aunque hubiera fallado en el ambiente tridentino, habría podido proveer preciosas experiencias para el futuro.

\section{Itinerario de la invitación a los observadores en las comisiones conciliares}

El proyecto "Invitación de observadores no católicos" comenzó a ser examinado cuidadosamente durante las sesiones preparatorias del Concilio Vaticano II, incluso ya desde los trabajos de la fase antepreparatoria y preparatoria, de acuerdo con las instrucciones del papa Juan XXIII, quien había afirmado su disponibilidad de acoger a los representantes de los "hermanos separados" en caso de que ellos quisieran asistir al Concilio.

Después de numerosas reuniones, deliberaciones y votaciones consultivas, la iniciativa de invitar a representantes oficiales de las otras comunidades cristianas al Concilio, en calidad de "observadores", fue delineada y presentada por el cardenal Agostino Bea, en un "Estatuto" especial que, por encargo del Papa, había elaborado para presentar a la Comisión Central Preparatoria pocos meses antes de la creación oficial del Secretariado para la Unión de los Cristianos.

El "Estatuto de los observadores" fue discutido, sometido a votación y aprobado, pero faltaba claridad sobre quién debía ocuparse de las invitaciones; la Comisión preconciliar para las Iglesias Orientales sostenía que a ella correspondía por derecho esta tarea, pero al contactar al patriarca Atenágoras I $^{15}$ de Constantinopla, este hizo

${ }^{14}$ De Simone, "L'invito di Pio IV ad Ivan IV Zar di Russia per la partecipazione al Concilio di Trento", 342-363.

${ }^{15}$ Atenágoras I (Aristokles Pyrou). Tsaraplana (Grecia), 25 de marzo de1886-Estambul (Turquía), 6 de julio de 1972. Fue Patriarca ecuménico de Constantinopla (1949-1972). Se encontró con el papa Pablo VI en su viaje como peregrino a Jerusalén, en enero de 1964. Así comenzó un "diálogo de la caridad” entre Roma y Constantinopla y una sincera amistad entre los dos hombres. El 7 diciembre 1965, en la conclusión del Concilio Vaticano II, en el cual habían participado observadores ortodoxos, fueron abrogados los anatemas de 1054, que habían simbolizado la escisión de la cristiandad oriental y occidental. En junio 1967, Pablo VI viajó a Estambul y, en signo de reparación, se arrodilló en Santa Sofía en el mismo lugar donde los delegados romanos habían lanzado los anatemas. En octubre 1967, Atenágoras se encontró con Pablo VI en Roma, donde celebró una liturgia de paz y de perdón y rindió 
saber que dicha Comisión no era el interlocutor más apreciado debido a la susceptibilidad de los ortodoxos respecto del problema de los uniatas. Por ello correspondió al Secretariado para la Unión de los Cristianos retomar los contactos.

En efecto, las cartas de invitación enviadas a las iglesias no católicas -firmadas por el cardenal Bea y monseñor Johannes Willebrands, presidente y secretario del Secretariado para la Unión de los Cristianos, respectivamente, en nombre del santo Padre-, presentaron el "Estatuto de los observadores", que precisó la naturaleza y el papel de estos en cuatro puntos:

I. Los observadores ofrecerán a las iglesias separadas de Roma una información veraz sobre el acontecimiento del Concilio.

II. Ellos podrán asistir a las sesiones públicas solemnes y a las asambleas generales donde serán discutidos los decretos del Concilio. Ellos no asistirán a las sesiones de comisión, salvo en ciertos casos particulares y con autorización especial.

III. Ellos no tendrán derecho a la palabra ni al voto.

IV. El Secretariado para la Unión de los Cristianos servirá de intermediario entre los organismos del Concilio y los observadores, para suministrar a estos las informaciones necesarias para que sigan fácilmente y de modo más eficaz los trabajos del Concilio, y organizará para ellos coloquios con personas calificadas, que podrían ser los mismos padres conciliares, sobre los temas discutidos al Concilio. ${ }^{16}$

Tales planteamientos se encuentran también en el "Reglamento del Concilio", cuyo Artículo 18, del capítulo noveno de la primera parte, describe otros derechos y deberes de los observadores:

1. Los observadores pueden informar a sus comunidades sobre problemas tratados en la sede Conciliar. Están por esto obligados a mantener el secreto sobre los mismos ante los demás, igual que todos los padres del Concilio, según establece el Artículo 26.

2. El Secretariado para la Promoción de la Unidad de los Cristianos regula las relaciones entre el Concilio y los observadores, de tal manera que estos puedan seguir los trabajos del Concilio. ${ }^{17}$

homenaje a las tumbas de Pedro y Pablo (N. Lossky; G. Cereti; A. Filippi; y L. Sartori, eds., Dizionario del movimento ecumenico [Bologna: Edizioni Dehoniane Bologna, 1994], 69-70).

${ }^{16}$ Wenger, Le Concile Vatican II. Croniques des sessions du Concile. Vol. I. Cronique de la Ire session, 194-195. [Traducción del autor].

${ }^{17}$ Sacrosanctum Oecumenicum Concilium Vaticanum Secundum-Ordo Concilii Oecumenici Vaticani Secundi Celebrandi, “Textus emendatus et promulgatus”, Vol. IV, Pars I, 261-262. [Traducción del autor]. 


\section{Negociaciones con las iglesias ortodoxas}

\section{Negociaciones con el Patriarcado de Constantinopla}

La invitación a los observadores de las iglesias ortodoxas fue hecha, en un primer momento, por medio del Patriarcado Ecuménico de Constantinopla, en 1962. Esto, debido a que la Iglesia Católica tuvo en cuenta la decisión de todas las iglesias ortodoxas, reunidas en la I Conferencia Panortodoxa de Rodas ${ }^{18}$, según la cual estas tomarían una actitud común en las cuestiones referentes a los intereses de toda la ortodoxia.

En consecuencia, la Iglesia Católica consideró oportuno transmitir la invitación a participar en el Concilio de manera conjunta, por medio del Patriarcado Ecuménico, y no de manera separada, a cada iglesia ortodoxa particular.

Con excepción del Patriarcado de Moscú, las demás iglesias ortodoxas enviaron su respuesta a Constantinopla. Sin la anuencia de Moscú, el patriarca Atenágoras -en nombre de toda la ortodoxia y queriendo mantener su unidad- dio respuesta negativa a la invitación de la Iglesia Católica e informó a Roma sobre la imposibilidad de mandar observadores ortodoxos al Concilio, al cual le deseaba total éxito.

Por eso, quedó absolutamente sorprendido cuando el Patriarcado de Moscú envió dos observadores a la primera sesión del Concilio, a pesar de que el Patriarcado Ecuménico había telegrafiado dos veces a Moscú para reconfirmar su posición sobre el particular. En este caso, la Iglesia Ortodoxa Rusa actuó de modo totalmente independiente, sin tener en cuenta la opinión de las otras iglesias ortodoxas y, sobre todo, el interés del Patriarcado Ecuménico de dar a Roma una respuesta colegial de toda la ortodoxia, según se había acordado durante la I Conferencia Panortodoxa de Rodas ${ }^{19}$.

\footnotetext{
${ }^{18}$ Fue convocada por el patriarca Atenágoras I, del 24 de septiembre al $1^{\circ}$ de octubre de 1961, en la isla griega de Rodas, con la participación de todas las iglesias ortodoxas.

${ }^{19}$ Fesquet, Diario del Concilio. Tutto il Concilio giorno per giorno, 30. "Finalmente, he aquí la tercera sorpresa del Concilio y no la menor: la presencia de observadores rusos. Esta situación es doblemente paradójica: en efecto, el Patriarcado de Moscú había manifestado en más de una ocasión, como es sabido, su desdeńo. Un artículo aparecido en la revista del Patriarcado había sido, ni más ni menos, titulado "Non possumus". Por otra parte, si Moscú está presente contra toda expectativa, ya desde el inicio del Concilio, ninguno en cambio representa a la Iglesia de Constantinopla, cuyo Patriarca se había manifestado constantemente muy favorable a las iniciativas ecuménicas de Juan XXIII. ¿Por qué este brusco cambio por parte de Moscú? ¿Es solo el Kremlin que ha provocado indirectamente, después del viaje de monseñor Willebrands, la auspiciada pacificación? ¿Es el deseo del patriarca Alexis y del gobierno soviético demostrar su independencia en relación con Constantinopla?” (ibíd.).
} 


\section{Negociaciones con el Patriarcado de Moscú}

El primer contacto se hizo por medio de cartas y encuentros personales entre el arcipreste Vitali Borovoi ${ }^{20}$, representante permanente del Patriarcado de Moscú al Consejo Ecuménico de las Iglesias (quien habría de ser un futuro observador delegado de la Iglesia Ortodoxa Rusa al Concilio Vaticano II), y monseñor Johannes Willebrands, secretario del Secretariado para la Unión de los Cristianos.

Posteriormente, monseñor Willebrands se reunió con el metropolita Nikodim, responsable del Departamento de Relaciones Exteriores del Patriarcado de Moscú, y conversaron implícitamente sobre la necesidad y las ventajas de hacer conocer a las autoridades religiosas de Moscú, de manera más directa, el pensamiento del papa Juan XXIII sobre el Concilio, de modo que esta información de primera mano fuese un elemento indispensable para la toma de posición del Patriarcado de Moscú frente al Concilio y el envío de observadores a este. Al respecto, el Patriarcado habría hecho entender su deseo de recibir una invitación directa por parte de Roma antes de dar respuesta definitiva a la cuestión del envío de observadores al Concilio.

En otro encuentro, de carácter reservado, entre el metropolita Nikodim y el cardenal Eugenio Tisserant, que tuvo lugar en Metz, se discutieron las "garantías en lo que se refería a la actitud apolítica del Concilio". El cardenal pudo decirle al metropolita que, en el Concilio, no habría ninguna condena explícita del comunismo, ya que -algunos meses antes- la Comisión Central Preparatoria había decidido no usar el término políticamente equívoco de "comunismo" y lo había sustituido por el de "materialismo ateo". En esta reunión también se ultimaron detalles para un viaje de monseñor Willebrands a Moscú.

El objetivo primordial del viaje era explicar a las autoridades religiosas de Moscú la naturaleza y los fines últimos del Concilio en tres pasos: (1) Ilustrar las intenciones que habían movido al papa Juan XXIII a convocar el Concilio, claramente expresadas ya en la constitución apostólica Humanae salutis. (2) Informar sobre la creación y finalidad del Secretariado para la Unión de los Cristianos. (3) Comunicar el deseo del

\footnotetext{
${ }^{20}$ Vitali Borovoi. Bielorrusia, 18 de enero de 1916-Rusia, 7 de abril de 2008. Fue representante de la Iglesia Ortodoxa Rusa ante el Consejo Ecuménico de las Iglesias, en los periodos 1962-1966 y 1978-1985. Fue observador en el Concilio Vaticano II entre 1962 y 1965, y miembro del Grupo Mixto de Trabajo entre la Iglesia Católica Romana y el Consejo Ecuménico de las Iglesias entre 1965 y 1972. Después de ordenado, fue vicepresidente del Seminario Teológico de Minsk y profesor de Historia Cristiana Antigua en la Academia Teológica de Leningrado, decano de la Catedral patriarcal de Moscú y profesor de Historia Eclesiástica Bizantina en la Academia Teológica de Moscú. Desde 1985 sirvió como vicepresidente del Departamento de Relaciones Exteriores de la Iglesia del Patriarcado de Moscú (N. Lossky; G. Cereti; A. Filippi; y L. Sartori, eds., Dizionario del movimento ecumenico [Bologna: Edizioni Dehoniane Bologna, 1994], 112).
} 
Papa de que los cristianos no católicos participasen de algún modo al Concilio, punto en el que preguntaba tan solo si una eventual invitación oficial sería considerada responsablemente.

Después de haber examinado el informe de monseñor Willebrands, tras su regreso de Moscú a Roma, el cardenal Agostino Bea dirigió al metropolita Nikodim un telegrama, en el cual le informaba sobre el envío inminente de una invitación oficial del Vaticano al patriarca Alexis I de Moscú. El mismo día, la Santa Sede envió las invitaciones oficiales al Patriarcado Ruso. Al recibirlas, el Santo Sínodo de la Iglesia Ortodoxa Rusa, bajo la Presidencia del patriarca Alexis, examinó la invitación de Roma, así como los informes que el metropolita Nikodim había elaborado junto a monseñor Willebrands, sobre la preparación del Concilio Vaticano II de la Iglesia Católica Romana.

A la luz de tales informes, el Santo Sínodo tomó la decisión histórica de enviar observadores delegados al Concilio. La Revista del Patriarcado de Moscú informó sobre esta respuesta de la Iglesia rusa en los siguientes términos:

I. Aceptar la invitación a enviar al Concilio Vaticano II, de la Iglesia Católica, observadores del Patriarcado de Moscú.

II. Nombrar-como observadores del Patriarcado de Moscú al Concilio Vaticano II- al representante de la Iglesia Ortodoxa Rusa ante el Consejo Ecuménico de las Iglesias, profesor en la Academia Eclesiástica de Leningrado, arcipreste Vitali Borovoi, y al jefe de la Misión Espiritual Rusa de Jerusalén, archimandrita Vladimir Kotliarov. ${ }^{21}$

III. Disponer el siguiente ordenamiento para los observadores del Patriarcado de Moscú al Concilio Vaticano II: (a) Los observadores informarán detalladamente al Patriarcado de Moscú sobre el trabajo del Concilio Vaticano II y sobre las reacciones por este provocadas en el ambiente eclesiástico y social. Ellos presentarán regularmente, al menos una vez por semana, un informe sobre los estudios conciliares al jefe del Departamento Eclesiástico de Relaciones Exte-

\footnotetext{
${ }^{21}$ Vladimir Kotliarov. Aktobe (Kazajistán), 27 de mayo de1929. Fue ordenado en 1953 y prosiguió su formación en la Academia Teológica de Leningrado donde recibió el Doctorado en Teología en 1958. En 1962 fue enviado a Jerusalén como miembro de la Misión Eclesiástica rusa. Fue uno de los observadores de la Iglesia Ortodoxa Rusa en el Concilio Vaticano II. Fue representante del Patriarcado ruso ante el Consejo Ecuménico de las Iglesias. En 1965 ejerció como embajador del Patriarcado de Moscú ante el Patriarcado Ortodoxo de Antioquía. En 1966 fue transferido a la diócesis ortodoxa de Berlín con el título de exarca patriarcal de todas las parroquias rusas de Europa Central. En 1967 fue nombrado arzobispo, y en 1992, metropolita. Actualmente es metropolita emérito de San Petersburgo y Ladoga, y miembro del santo Sínodo de la Iglesia Ortodoxa Rusa (N. Lossky; G. Cereti; A. Filippi; y L. Sartori, eds., Dizionario del movimento ecumenico [Bologna: Edizioni Dehoniane Bologna, 1994], 562).
} 
riores, arzobispo Nikodim, de Yaroslav y Rostov, enviando al mismo tiempo material impreso sobre el Concilio y las publicaciones y revistas relativas. (b) En su calidad de observadores conciliares, los observadores ilustrarán, si necesario, la posición del Patriarcado de Moscú a las instituciones competentes de la Iglesia Católica Romana.

IV. Encargar al jefe del Departamento Eclesiástico de Relaciones Exteriores del Patriarcado de Moscú, el arzobispo Nikodim, de Yaroslav y Rostov, de informar regularmente al Santo Sínodo sobre los trabajos del Concilio Vaticano II. ${ }^{22}$

\section{Una llegada insospechada y una presencia motivante}

Casi al final del mismo día de apertura del Concilio, hacia las ocho de la noche, el Secretariado para la Unión de los Cristianos recibió un telegrama proveniente de Moscú, en el cual el Patriarcado Ruso le comunicaba la decisión de enviar dos observadores delegados al Concilio y los nombres de dichos representantes ${ }^{23}$. El día después, el Secretariado confirmó oficialmente la noticia con el siguiente comunicado:

Con motivo de las noticias difundidas en estos días por las agencias de información, el Secretariado para la Unión de los Cristianos comunica oficialmente que la Iglesia Patriarcal de Rusia ha anunciado, con un telegrama de fecha 11 octubre, la designación de dos observadores delegados al Concilio: el arcipreste Vitali Borovoi y el archimandrita Vladimir Kotliarov. ${ }^{24}$

Los dos observadores rusos llegaron a Roma al mediodía del viernes 12 de octubre y se alojaron en la Pensión Castello, en las cercanías de Castel Sant'Angelo ${ }^{25}$. Fueron alcanzados algunos días después por Nikolai Anfinoghenov, secretario de la

\footnotetext{
${ }^{22}$ Nikodim, Uno scomodo ottimista Giovanni XXIII, 154. [Traducción del autor].

${ }^{23}$ Riccardi, Il Vaticano e Mosca. 1940-1990, 288. La decisión del Santo Sínodo de enviar observadores de la Iglesia Ortodoxa Rusa al Concilio había sido tomada el día 10 octubre; pero el Patriarcado ruso esperó casi hasta el final del 11 octubre para informar al Secretariado para la Unión de los Cristianos. Algún autor sostiene que probablemente eso se debió a que el Patriarcado de Moscú quiso esperar hasta el final para conocer las palabras del Papa en su discurso inaugural del Concilio, como el último "requisito" o "garantía” necesaria para que los observadores rusos pudiesen partir desde Moscú hacia Roma. En efecto, es posible presumir que, si el Papa, en su alocución, hubiese hecho alguna alusión, aunque fuera mínima, al comunismo o a la oposición de la Iglesia al mismo, muy probablemente los observadores rusos no se habrían movido de Moscú para partir hacia Roma (ibíd.).

${ }^{24}$ Wenger, Le Concile Vatican II. Croniques des sessions du Concile. Vol. I. Cronique de la Ire session, 230. [Traducción del autor].

${ }^{25}$ Edelby, Il Vaticano II nel diario di un vescovo arabo, 54; 56. En la misma pensión se alojaban los otros observadores orientales (dos coptos, dos etíopes, un armeno, un sirio y dos rusos de la emigración). Junto a ellos se alojaba también el padre Pierre Duprey, miembro del Secretariado para la Unión de los
} 
representación del Patriarcado de Moscú ante el Consejo Ecuménico de las Iglesias en Ginebra, llegado a Roma el 16 de octubre para servir como sustituto e intérprete a los dos observadores de la Iglesia Ortodoxa Rusa.

Durante esta primera sesión del Concilio, los observadores de la Iglesia Ortodoxa Rusa fueron los únicos representantes de las iglesias ortodoxas calcedonianas. Su presencia suscitó verdadero interés, especialmente por parte de los medios de comunicación, que a menudo buscaron acercárseles para establecer con ellos entrevistas y coloquios ${ }^{26}$.

Durante el Concilio, los observadores tuvieron un puesto realmente privilegiado en el aula conciliar: debajo de la tribuna de San Longinus, muy cerca de la mesa de la Presidencia y de los padres cardenales. Ellos mismos crearon un comité especial de coordinación para acordar quiénes serían sus voceros en las diferentes audiencias y recibimientos.

\section{Vida y actividad de los observadores durante el concilio}

¿Qué hacían los observadores durante el Concilio? ¿Cómo transcurría para ellos una jornada en Roma? Aquí es necesario tener en cuenta las actividades que tenían dentro y fuera del aula conciliar.

\section{Dentro del aula conciliar}

(1) Asistían a todas las congregaciones generales, y así pudieron seguir plenamente el desarrollo de los trabajos. (2) Participaban de la liturgia y de las oraciones con las cuales iniciaba la jornada, antes del inicio de los trabajos propiamente dichos ${ }^{27}$.

Cristianos y encargado de estar al tanto de las eventuales necesidades de estos huéspedes tan gratos al Secretariado y al Concilio (ibíd.).

${ }^{26}$ Mientras que la Iglesia Ortodoxa Rusa se hacía presente en el Concilio Vaticano II, mediante sus dos observadores delegados, la URSS enviaba como periodista acreditado, para cubrir las cuatro sesiones conciliares, a M.P. Mcedlov, representante de la Literaturnaia Gazeta soviética. De esta manera, los soviéticos podían tener noticias de primera mano sobre el desarrollo del Concilio y, por consiguiente, sobre los cambios acontecidos al interior de la Iglesia Católica y sus directrices doctrinales. Junto a Mcedlov, otros autores soviéticos -como Velikovich, Markevich y Niunka- escribieron artículos y obras en las cuales presentaron un juicio sobre el Concilio. Francesco Skoda recoge de modo global algunos de estos juicios sobre el Concilio, teniendo en cuenta que son hechos desde el punto de vista de autores soviéticos, en Il Concilio Vaticano nella critica soviética (Torino: Elle Di Ci, 1970), 122-128.

${ }^{27}$ Camara, Roma, due del mattino. Lettere dal Concilio Vaticano II, 378. "Ver a los observadores no católicos unirse a nuestras mismas oraciones y a nuestros cantos es alegría pura. Y hay un momento en el cual somos todos una cosa sola: el canto del Pater noster..." (ibíd.). 
(3) Leían y seguían la exposición y la discusión entre los padres conciliares, de los documentos propuestos del día. Es de notar como todos ellos -fueran observadores o huéspedes- tenían a disposición los mismos documentos de los padres conciliares, sin excepción alguna. (4) Escuchaban las intervenciones de los padres, acudiendo si era necesario a los intérpretes puestos a su disposición. (5) Emprendían contactos y coloquios con los padres y los peritos conciliares, durante los intervalos, en los dos bares disponibles en el aula conciliar ${ }^{28}$.

\section{Fuera del aula conciliar}

(1) Como observadores, preparaban los informes periódicos que enviaban a sus respectivas iglesias, a las que mantenían informadas de primera mano sobre el proseguimiento del Concilio. (2) Leían y estudiaban los esquemas a ellos confiados por parte del Secretariado. (3) Participaban de las reuniones del martes, organizadas expresamente para ellos por el Secretariado, con el fin de hablar, dar la propia opinión, aclarar, pedir ampliaciones, explicaciones, profundizaciones, etc., al personal del Secretariado o a personas expertas, invitadas por este. (4) Participaban de las reuniones del viernes, coordinadas por ellos mismos, con el fin de conocerse mejor entre sí y de acordar estrategias comunes y evaluaciones de los trabajos, además de orar por el Concilio y la unidad de los cristianos. Estas reuniones tenían lugar casi siempre en el apartamento puesto a disposición por la Comunidad Ecuménica de Taizé, ubicado en Via del Plebiscito, No. 107. (5) Concedían entrevistas a órganos de información y conferencias a universidades, seminarios romanos, centros de documentación y de información, conventos y casas religiosas. (6) Eran invitados a actividades académicas, por ejemplo, la defensa en la Universidad Gregoriana, de la tesis del jesuita alemán Norbert Lohfink, del Pontificio Instituto Bíblico. (7) Se beneficiaban de los contactos con los padres y los peritos conciliares, en San Pedro, o en sus alrededores, o atendían invitaciones privadas a almuerzo o cena en casa de obispos y cardenales. (8) Participaban a las actividades especialmente programadas para ellos por parte del Secretariado, por ejemplo, excursiones de grupo para conocer lugares históricos de Roma y de Italia (Biblioteca y museos vaticanos, Subiaco, Excavaciones de San Pedro, Grottaferrata,

${ }^{28}$ Guasco, La Chiesa del Vaticano II (1958-1978), Parte 1, 215-216. "Durante estas largas sesiones, los padres podían pasar algunos momentos de distensión en los dos bares puestos a su disposición (en los cuales se servían gratuitamente solo bebidas no alcohólicas): el célebre 'bar de los canónicos', puesto en la sacristía, y el que instalaron en la nave lateral derecha (apodados Bar Jonas y Bar Abbas). Estos ambientes desempeñaron 'un rol importante', porque eran lugares de encuentros particularmente fecundos entre obispos, teólogos y observadores que, dispersos en varias partes de Roma, no hubieran tenido normalmente otra posibilidad de encontrarse e intercambiar impresiones y proyectos" (ibíd.). 
Monte Casino, Catacumbas). (9) Oraban juntos por el buen proseguimiento del Concilio, organizando dos servicios regulares, los lunes y los viernes en la mañana, en la Capilla Metodista Inglesa de Roma, cerca de Ponte Sant'Angelo. (10) Organizaban encuentros más limitados por grupos lingüísticos con el objetivo de profundizar y discutir argumentos determinados.

\section{Los observadores y el Patriarcado ruso hablan de la primera sesión del Concilio}

El arcipreste Vitali Borovoi, al responder a las preguntas de un entrevistador de la agencia Kipa-Concilie, subrayaba "la atmósfera llena de libertad, que permite a los padres conciliares exponer opiniones diversas; atmósfera saturada de benevolencia y de sentimientos fraternos hacia los otros cristianos no católicos" ${ }^{29}$; también quiso mencionar la grata impresión tenida por "la actitud tan amigable que se ha tenido hacia

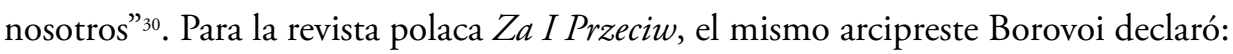

Está fuera de duda que el pontificado del papa Juan ha contribuido sensiblemente a crear un nuevo clima en nuestras relaciones recíprocas y en las de la humanidad entera. [...]. Dado mi carácter de observador delegado y las normas relativas a las cuales debo sujetarme, no me es posible dar un juicio sobre las actividades desarrolladas en el Vaticano II. Me limitaré a subrayar la atmósfera llena de libertad que ha permitido a los padres conciliares exponer opiniones diversas, la atmósfera de benevolencia y de sentimientos fraternos hacia los otros cristianos, y la actitud de amistad por parte de la mayoría de los miembros del Concilio en sus relaciones conmigo. ${ }^{31}$

A la pregunta de un entrevistador de la revista Oriente cristiano sobre el Concilio y sus impresiones después de haber asistido a la primera sesión, los observadores rusos Borovoi y Kotliarov respondieron del siguiente modo:

Este Concilio es verdaderamente un gran acontecimiento, y esto por la importancia de los argumentos tratados, por el número de los obispos llegados para participar en él, por el modo como se desarrolla. [...]. Se trata entonces

${ }^{29}$ Camara, Roma, due del mattino. Lettere dal Concilio Vaticano II, 53 y 55. "Los observadores no católicos están sorprendidos de la libertad absoluta de que gozan los padres conciliares". "El santo Padre considera fundamental -sobre todo pensando en los observadores no católicos- la total libertad de los padres conciliares" (ibíd.).

${ }^{30}$ Fouilloux, "Des observateurs non catholiques", 248-249. Vitali Borovoi, en el informe confidencial para su Iglesia, de enero-febrero de 1963, en la página 8, afirmaba: "Muchos de los padres del Concilio rompieron las reglas del procedimiento dirigiendo sus discursos no solo a sus colegas, los miembros del Concilio, sino también directamente a los observadores (dilettissimi fratres observatores)" (ibíd.).

${ }^{31}$ Revista Ecclesia, "Los observadores hablan del Concilio. Algunas de sus declaraciones después de la primera sesión”, 23-24. 
en gran parte de argumentos internos de la Iglesia Católica, pero por esto no menos importantes y actuales. Se trata de la impostación de problemas que en definitiva reflejan aquellos que afloran cotidianamente en la vida interna de cada una de las iglesias, especialmente en lo que tiene que ver con su aggiornamento o puesta al día, con vistas a convertirse en instrumentos siempre más aptos de la difusión del mensaje divino de Cristo.

Impresionante es el número de los obispos que participan, sobre todo porque ellos provienen de cada parte del mundo y representan por tanto las exigencias de fieles que viven en las condiciones más diversas y bajo concepciones políticas, culturales y económicas muy diferentes.

En cuanto al modo como se desarrollan las discusiones, dejadnos decir que hemos quedado verdaderamente sorprendidos por la libertad y democracia de las intervenciones, porque a cada obispo es dejado el modo de expresar libremente su pensamiento y someterlo a la aprobación de los otros obispos. Todo esto nos ha impresionado, porque no creíamos que en la Iglesia Católica hubiese tanta libertad de discusión. Hemos quedado mucho más gratamente impresionados en cuanto este sentido democrático, del cual hemos sido testigos, nos permite esperar que también en las relaciones con las iglesias no católicas será más fácil encauzar el diálogo y poner las bases para una serena discusión. ${ }^{32}$

Y en otras entrevistas declaraban que el primer gran éxito del Concilio había sido justamente el mejoramiento de las relaciones entre los cristianos. En efecto, los observadores rusos no encontraron jamás dificultad o desconfianza en sus relaciones con el Secretariado, el Consejo de Presidencia y los padres conciliares ${ }^{33}$.

La Revista del Patriarcado de Moscú, en su número de mayo 1963, evaluaba así los resultados de la primera sesión del Concilio:

Después de la primera sesión (11 de octubre-7 de diciembre de 1962) el significado del Concilio Vaticano II viene ya reconocido por todos, en particular modo, por los cambios significativos y fundamentales que se delinean no solo en la vida interior de la Iglesia Católica, como también en sus relaciones con el mundo externo.

Es suficiente mirar los datos publicados en los últimos tiempos por la prensa mundial para convencerse de que un cambio importante en la actividad y en la estructura de la Iglesia romana no podía dejar de influenciar a la masa de personas que de ella depende. En 1962, la grey de esta Iglesia sumaba, según estadísticas católicas y protestantes, 558 millones de personas (es decir, el 18, $2 \%$ de la población mundial). Como centro de la suprema jerarquía de la Iglesia romana, cuyo episcopado proveniente de todo el mundo y reunido en Roma cuenta con cerca de 2.800 miembros, el Concilio es llamado a ser la más alta expresión de su vida litúrgica, exegética y jurídico-canónica.

\footnotetext{
${ }^{32}$ Revista Oriente Cristiano, “Sección dedicada al Concilio Vaticano II”, 24-25. [Traducción del autor].

${ }^{33}$ Caprile, Il Concilio Vaticano II. Cronache del Concilio Vaticano II. Vol. II. Il primo periodo, 1962-1963, 343.
} 
El Concilio de los obispos de la Iglesia apostólica es en sí un acontecimiento sacramental, litúrgico y divino, y representa una etapa nueva en la interpretación de la doctrina eclesial y en sus relaciones con los diversos campos de la vida humana. Finalmente, sus decisiones deben determinar la configuración futura de la vida de la Iglesia e introduce nuevas reformas en el orden eclesiástico. Como dijo Juan XXIII, el Concilio por él convocado viene a sacar "nueva fuerza" para la organización interna de la Iglesia romana. El Papa ha insistido repetidamente en el hecho de que la Iglesia debe adaptarse a las nuevas condiciones de su ministerio, y que después del cambio en la vida religiosa de los fieles es indispensable una renovación. La doctrina cristiana, aunque mantenga inmutada su esencia, debe ser formulada en modo diverso y nuevo que corresponda mayormente a la conciencia moderna del hombre.

El Concilio de la Iglesia, cual asamblea universal del episcopado católico, debe examinar, ante todo, las cuestiones de la doctrina. El aspecto dogmático de la vida de la Iglesia exige, de los padres conciliares, ser formulado en modo nuevo, como decía el Papa. En el campo de una renovación de la vida cristiana de su numerosa grey, el Concilio debe adentrarse en las necesidades y exigencias características de nuestra época. Esto exige también la adaptación de la disciplina eclesiástica a las necesidades de nuestro tiempo. ${ }^{34}$

\section{Lista de los observadores rusos al Concilio}

Estos son los participantes del Patriarcado de Moscú al Vaticano II: arcipreste Vitali Borovoi (estuvo en las cuatro sesiones del Concilio); archimandrita Vladimir Kotliarov (estuvo en la primera sesión del Concilio); arcipreste Jakov Ilich (estuvo en la segunda sesión del Concilio); arcipreste Liverij Voronov (estuvo en la tercera y cuarta sesión del Concilio); archimandrita Juvenali Poiarkov (estuvo en la cuarta sesión del Concilio); señor Nikolai Anfinoguenov (estuvo en la primera, segunda y cuarta sesión del Concilio); y señor Boris Nelubin (estuvo en la tercera y cuarta sesión del Concilio). Los cinco primeros participaron como observadores, y los dos últimos, como intérpretes ${ }^{35}$.

\section{Frutos ecuménicos de la presencia al Concilio}

La participación de los observadores al Concilio arrojó resultados y enseñanzas de inmediato y de largo plazo.

\footnotetext{
${ }^{34}$ Nikodim, Uno scomodo ottimista Giovanni XXIII, 191-192. [Traducción del autor].

${ }^{35}$ Sacrosanctum Oecumenicum Concilium Vaticanum Secundum, "Index Observatorum Delegatorum ad Concilium Vaticanum II et Hospitum Secretariatus ad Unitatem Christianorum Fovendam”, 276; Sacrosanctum Oecumenicum Concilium Vaticanum Secundum, "Observateurs-délégues et hôtes du Secrétariat pour L'Unité des Chrétiens au deuxième Concile Oecumenique du Vatican II”, 85.
} 


\section{Resultados inmediatos}

Hacia el final del Concilio, el papa Pablo VI podía hablar con los observadores no católicos sobre los frutos que juntos habían sembrado y recogido durante y al término del Vaticano II: la conciencia general acerca del problema del restablecimiento de la unión de la Iglesia una y del compromiso de todos los cristianos de trabajar por este deseo del Señor; el conocimiento recíproco como personas y como comunidades cristianas vivas, orantes y operantes en el nombre de Cristo; el reconocimiento de los propios errores y de ciertos sentimientos negativos mutuos, por los cuales se había pedido perdón al Señor y a los hermanos, al descubrir su raíz no cristiana, y la voluntad de transformarlos en sentimientos dignos de la escuela de Cristo; la conquista de comenzar a amarse y haber restablecido una comunión recíproca en la caridad, para que el mundo reconociera en ello su condición de discípulos de Cristo; la reanudación de relaciones humanas, serenas, bienhechoras y confiadas; y el comenzar a orar juntos.

Otros resultados inmediatos son los siguientes: la creación del Instituto Ecuménico de Jerusalén de estudio sobre la Historia de la Salvación; el comenzar a pensar teológicamente sobre la unión como reconocimiento de los valores del otro al interior de la Iglesia universal; las contribuciones de los observadores, con sus sugerencias, para mejorar y hacer más concretos algunos documentos conciliares, como el decreto sobre el ecumenismo Unitatis redintegratio y la declaración sobre la libertad religiosa Nostra aetate; el reconocimiento abierto de la eclesialidad más completa de las iglesias orientales no unidas, en los documentos conciliares; el trabajo por una causa común, cual es la renovación de la Iglesia Católica en un Concilio, en el cual se dio espacio a la escucha de otras voces y opiniones que aportaron mucho a sus resultados; la oración conjunta y el aprendizaje adquirido por todos, tanto de los otros como de sí mismos ${ }^{36}$; la finalización de una etapa de indiferencia oficial entre católicos y ortodoxos que duró siglos y el comienzo de otra marcada por el encuentro en la caridad entre ellos, y el cambio radical de mentalidad y de método en el momento de afrontar la cuestión "concerniente al problema" de la unión de los cristianos ${ }^{37}$. Con su presencia,

${ }^{36}$ Tamborra, Chiesa cattolica e Ortodossia russa. Due secoli di confronto e dialogo. Dalla Santa Alleanza ai nostri giorni. Anota el mismo autor: “...en el Concilio Vaticano II los padres conciliares advirtieron que el Oriente cristiano podía aportar también una contribución a la renovación de la misma Iglesia Católica. De la otra parte, ortodoxa, el 'reflejarse' en la Iglesia de Occidente que se había acentuado desde la segunda mitad del siglo XIX se traducía en un mayor conocimiento de sí mismos, de las propias cuestiones y necesidades, en la convicción creciente de deber iniciar un indispensable aggiornamento teológico-cultural. Los unos tenían necesidad de los otros y solo una Iglesia nueva y unida podía satisfacer esta exigencia” (ibíd., 443).

${ }^{37}$ Ibíd., 444-445. "La presencia en seno al Concilio Vaticano también de ortodoxos y reformados de variada observancia estaba destinada sucesivamente a promover encuentros, solicitar aclaraciones, 
los observadores habían manifestado de manera inequívoca, a todo el mundo, su buena voluntad de buscar los caminos hacia la unión ${ }^{38}$.

Un ejemplo notable de los frutos y de la importancia de la participación de los observadores de la Iglesia Ortodoxa Rusa en el Concilio Vaticano II fue el cambio progresivo de la actitud del metropolita Nikodim de Leningrado, jefe del Departamento para Asuntos Exteriores del Patriarcado de Moscú, hacia el Concilio y la Iglesia Católica.

Este cambio se advierte al confrontar sus primeras declaraciones acerca del anuncio del Vaticano II -en las cuales atacó frontalmente la "política vaticana" y expresó su total desacuerdo con ella- con los hechos por él protagonizados durante y después del Concilio: hizo dos visitas oficiales al papa Pablo VI; participó en las ceremonias de clausura del Concilio Vaticano II; hizo retiros de un mes con los padres jesuitas, para hacer los ejercicios ignacianos; escribió una tesis doctoral sobre el papa Juan XXIII, en la Academia Teológica de Leningrado; permitió el intercambio de estudiantes ortodoxos con estudiantes de las universidades romanas y la recensión de libros de Roma para las bibliotecas rusas ortodoxas; peregrinó a los principales santuarios marianos de Europa e hizo una visita oficial al papa Juan Pablo I.

En otras palabras, la participación de los observadores en el Concilio permitió -como fue el caso del metropolita Nikodim- eliminar preconceptos, prejuicios y prevenciones hacia otros cristianos, de manera especial, hacia los católicos. En este caso particular ayudó su posición como responsable del Departamento para Asuntos Exteriores del Patriarcado de Moscú, ya que Nikodim era el primero en recibir y leer los Informes o Relaciones que los observadores rusos enviaban periódicamente desde Roma hasta Moscú y Leningrado sobre el curso del Concilio; y esa fue, sin lugar

definir interpretaciones. La búsqueda de un lenguaje teológico-cultural común con el cual entenderse, alcanzar una unicidad de conceptos y de términos, el esfuerzo de acercar mentalidades diferentes, todo esto y más todavía fue propiciado por los encuentros conciliares. Gracias a ellos, toda una mentalidad ha comenzado precisamente a cambiar. A diferencia de un siglo antes, cuando encerrarse en las propias posiciones era considerado esencial, fundamental, del Concilio en adelante el principio del diálogo ha tomado la ventaja: entender al otro y hacer entender las propias posiciones, fruto de siglos transcurridos por un camino diferente; dar un significado no equivocado, antes bien único y plenamente aceptado a los términos y a las expresiones; saber escuchar a los otros con la paciencia y la ductilidad necesarias. Ciertamente los problemas por afrontar no eran ni simples ni fáciles, pero gracias a este método nuevo y por todos aceptado, sólidas bases se edificaron para futuros progresos" (ibíd., 444-445).

${ }^{38}$ Juan Pablo II, "Carta encíclica Ut unum sint sobre el compromiso ecuménico" 50. “...el vínculo con las Iglesias de Oriente, resquebrajado durante siglos, es reforzado con el Concilio Vaticano II. Los Observadores de estas iglesias presentes al Concilio, junto a los representantes de las iglesias y comunidades eclesiales de Occidente, han manifestado públicamente, en un momento así, tan solemne para la Iglesia Católica, la común voluntad de buscar la comunión" (ibíd.). 
a dudas, una oportunidad óptima para profundizar un conocimiento veraz sobre lo que proyectaba el Vaticano II.

Lo anterior nos muestra la importancia del trato frecuente y recíproco entre los cristianos, que posibilita la creación de amistades que perduran y se siguen desarrollando con el tiempo. El contacto directo, jamás sustituible por los libros o el estudio, es fundamental para construir el camino hacia la unión: es necesario conocerse para poderse amar. El ecumenismo real y concreto brota del encuentro y del contacto entre las personas. Es claro que, con la experiencia de los observadores rusos al Concilio, Nikodim aprendió a amar más la Iglesia una, la Iglesia toda, y abrió su intelecto y su corazón al diálogo y a la amistad con hermanos con los cuales compartía la misma fe.

\section{A largo plazo}

Otros frutos que se vieron después del Concilio, específicamente con la Iglesia Ortodoxa Rusa, fueron los siguientes: los diálogos sobre Iglesia y sociedad organizados conjuntamente por esta y la Iglesia Católica en 1967, en Leningrado, y en 1970, en Bari, Italia; el reconocimiento de los matrimonios mixtos en 1967; la presencia en Moscú de la delegación católica con motivo del quincuagésimo aniversario del restablecimiento del Patriarcado; las visitas del metropolita Nikodim a Alemania, Francia e Italia; la intercomunión sacramental aceptada en 1969; el mensaje del papa Pablo VI con ocasión de la muerte del patriarca Alexis I de Moscú (18 de abril de 1970) y el envío de una delegación del Vaticano a sus funerales; y la elaboración por parte del Secretariado para la Unión de los Cristianos de un directorio ecuménico, en dos partes: Ad totam Ecclesiam (14 de mayo de 1967) y Spiritus Domini (16 de abril de 1970), para la aplicación del decreto conciliar sobre el ecumenismo.

\section{Un balance de la Iglesia Ortodoxa Rusa}

Un artículo de la Revista del Patriarcado de Moscú de enero 1966, en el que se hace el balance de las actividades ecuménicas de la Iglesia Ortodoxa Rusa durante el año 1965, recuerda el recorrido cumplido respecto de las relaciones con la Iglesia Católica.

En la historia de las relaciones recíprocas entre nuestra Iglesia y la Iglesia Católica romana, el ańo 1965 ha aportado una serie de elementos sustanciales, entre los cuales en modo particular el intercambio de mensajes de buenos deseos entre el santísimo papa Pablo VI y el santísimo patriarca Alexis y el viaje a Rusia del obispo de Mauria Johannes Willebrands, secretario del Secretariado de la Iglesia Católica romana para la Unión de los Cristianos. También la presencia a la cuarta y última sesión del Concilio Vaticano II de los observadores de nuestra Iglesia, el arcipreste profesor Vitali Borovoi y el archimandrita Juvenali Poiarkov, ha 
tenido mucha importancia en crear una atmósfera benévola entre las iglesias Rusa y Católica romana. Los observadores han referido sistemáticamente al excelentísimo presidente de la Sección para las Relaciones Eclesiásticas Exteriores, el cual a su vez ha informado al Santo Sínodo de nuestra Iglesia sobre el trabajo que se desarrollaba al Concilio Vaticano. ${ }^{39}$

Así mismo, en un discurso dirigido al cardenal Agostino Bea, el arcipreste Vitali Borovoi expresó un balance muy positivo de su participación al Concilio:

...nosotros estamos felices de poder comunicar a las iglesias que nos han enviado, a las confesiones y a las asociaciones eclesiales, que aquí en Roma hemos sido testigos del modo como nuestros hermanos católicos romanos, en su Segundo Concilio Vaticano, con la oración y con gran celo pastoral, buscan las mejores vías para la renovación de su Iglesia y para el establecimiento de un diálogo fraterno en condiciones de igualdad con otros cristianos para "alabar juntos al Espíritu Santo". ${ }^{40}$

\section{Los contactos pontificios}

\section{Los papas y la Unión Soviética}

Durante el Vaticano II e incluso en su preparación, fueron cruciales las relaciones que los papas del Concilio sostuvieron con las autoridades religiosas y políticas de la Unión Soviética. Estas contribuyeron ampliamente a crear un ambiente propicio que facilitó la distensión, el entendimiento y la cooperación mutua.

Entre tales contactos son dignos de mencionar el intercambio de telegramas entre Nikita Kruschev ${ }^{41}$, presidente del Partido Comunista de la Unión Soviética, y Juan XXIII, con felicitaciones por el cumpleaños 80 del $\mathrm{Papa}^{42}$; saludos a propósito

\footnotetext{
${ }^{39}$ Revista Russia Cristiana, "Noticias sobre ecumenismo", 47. [Traducción del autor].

${ }^{40}$ Bea, Ecumenismo nel Concilio: tappe pubbliche di un sorprendente camino, 113-114. [Traducción del autor].

${ }^{41}$ Nikita Serguéievich Kruschev. Kalinova (Ucrania), 15 de abril de 1894-Moscú, 11 de septiembre de 1971. Fue dirigente de la Unión Soviética durante una parte de la Guerra Fría. Desempeñó las funciones de primer secretario del Partido Comunista de la Unión Soviética entre 1953 y 1964, y de presidente del Consejo de Ministros, de 1958 a 1964. Fue responsable de la desestalinización parcial de la Unión Soviética, para respaldar el progreso del programa espacial soviético y varias reformas relativamente liberales en materia de política interna. Sus colegas del partido lo retiraron del poder en 1964. Fue remplazado por Leonid Brézhnev como primer secretario y por Alekséi Kosygin como presidente del Consejo de Ministros.

${ }^{42}$ Zizola, L’utopia di papa Giovanni, 167; ídem, Giovanni XXIII. La fede e la politica, 181. El telegrama con ocasión del cumpleaños de Juan XXIII fue el primer toque de los soviéticos a la puerta del Papa de Roma desde la Revolución de octubre. Apenas leído el mensaje, el papa Juan comentó: "Esta es una buena noticia. Será necesario responder. Encontraremos la manera adecuada. Es un hilo de la Providencia y no tenemos el derecho de romperlo. Es ciertamente una buena señal, que se debe interpretar positivamente: siempre es mejor una caricia que una cachetadita, ¿verdad?” (ibíd.).
} 
de las fiestas navideñas de 1962; congratulaciones por el Premio Balzan por la Paz otorgado a Juan XXIII, y deseos por el restablecimiento de la salud del Pontífice.

También cuentan el intercambio de telegramas entre Juan XXIII y el patriarca de Moscú Alexis I, y la audiencia privada que este Papa concedió en el Vaticano a la hija de Kruschev, Rada Kruschova, y a su esposo Alexei Adjubei. En el mismo sentido se pueden mencionar las gestiones del mismo Papa, ante las autoridades soviéticas, en favor de la liberación del metropolita Josif Slipyj, arzobispo mayor de los ucranianos católicos de rito oriental, encarcelado desde hacía 18 años ${ }^{43}$.

El papa Pablo VI hizo lo propio, al intercambiar mensajes con el patriarca Alexis I, con ocasión de su ascenso al solio de San Pedro; envió saludos y una delegación pontificia a la Unión Soviética, con ocasión del jubileo sacerdotal del Patriarca; y se escribieron de nuevo con ocasión de la inauguración del pontificado. Pablo VI también recibió, en audiencia privada, en dos ocasiones, al metropolita Nikodim de Leningrado, miembro del Santo Sínodo y responsable del Departamento para los Asuntos Exteriores del Patriarcado de Moscú.

\section{Gestos ecuménicos de Juan XXIII y Pablo VI durante el Concilio}

Algunos gestos concretos de los papas del Vaticano II ayudaron a crear un clima propicio para que las relaciones con los hermanos de las otras iglesias se dieran de la mejor manera y sentaran las bases para crecer y avanzar en el trabajo ecuménico.

En el caso de Juan XXIII, se pueden mencionar los siguientes hechos: la creación del Secretariado para la Unión de los Cristianos, con el fin de ayudar a los no católicos a seguir los trabajos del Concilio; sus reiteradas solicitudes a los "hermanos separados" de orar por el éxito del Concilio; su acogida, en el Vaticano, a todos los cristianos no católicos que desearan reunirse con él; su invitación a las iglesias y comunidades cristianas no católicas a hacerse presentes con observadores delegados a los trabajos del Concilio; su encuentro cordial con los representantes oficiales de las iglesias no católicas, al inicio de la primera sesión conciliar, que era la primera reunión de esta naturaleza que tenía lugar después de las separaciones ocurridas en los siglos XI y XVI.

Respecto de los gestos de Pablo VI en favor de las relaciones con las iglesias no católicas, deben mencionarse los siguientes: las audiencias que ofreció siempre a los

\footnotetext{
${ }^{43}$ Sobre la situación vivida por la Iglesia Ortodoxa Rusa durante el régimen soviético véase a Ellis, $\mathrm{La}$ Chiesa Ortodossa Russa. una storia contemporanea, 436-490; Pospielovsky, The Russian Church under the Soviet Regime, 1917-1982, 327-385; y sobre la Iglesia Católica durante el régimen soviético, a Osipova, Si el mundo os odia, 34-194.
} 
observadores, al inicio y conclusión de cada sesión del Concilio; su visita a la abadía de Grottaferrata, centro de rito oriental en las afueras de Roma; su petición de perdón, en nombre de la Iglesia Católica, a las otras iglesias y comunidades cristianas, por cuanto a ella correspondiera de responsabilidad en la separación, y su oferta de perdón por las ofensas recibidas; su encuentro, en Tierra Santa, con los patriarcas ortodoxos Atenágoras I de Constantinopla, Benedictos de Jerusalén, y Yéguishé Derderian, patriarca armenio-ortodoxo (no calcedoniano) de Jerusalén. Pablo VI saludó y agradeció la presencia de los observadores de las otras iglesias al Concilio en su carta encíclica Ecclesiam suam; restituyó la reliquia de la cabeza de San Andrés Apóstol a la Iglesia metropolitana greco-ortodoxa de Patras ${ }^{44}$; envió mensaje a los padres de la III Conferencia Panortodoxa de Rodas; felicitó, con ocasión de la Navidad y de la Pascua, a los diferentes patriarcas ortodoxos; restituyó la reliquia de San Saba a la Iglesia Ortodoxa de Jerusalén; sostuvo un encuentro de oración con los observadores, al terminar el Concilio, en la Basílica de San Pablo Extramuros; y abolió las excomuniones entre las iglesias de Roma y Constantinopla.

\section{A manera de conclusión}

La presencia de los observadores ortodoxos y de las demás confesiones cristianas al Concilio Vaticano II permitió el inicio del "gran examen de conciencia de la Iglesia" acerca del problema de la unidad de sus miembros, deseada y orada por Cristo antes de su inmolación en la cruz ${ }^{45}$. Este hecho marcó de manera indeleble, no solo los trabajos del Concilio, sino la mentalidad de los padres conciliares y de los mismos observadores, y por medio suyo, de las comunidades eclesiales que representaban. Su permanencia al Concilio marcó un antes y un después en el trabajo ecuménico, ya que la relación directa con estos miembros de las otras comunidades cristianas representó, para muchos padres conciliares presentes al Vaticano II, su primer contacto real con el drama de la división entre los cristianos. La toma de conciencia de esta realidad y la necesidad de hacer algo al respecto por parte de todos fue, por sí solo, un gran logro.

${ }^{44}$ Camara, Roma, due del mattino. Lettere dal Concilio Vaticano II, 238. "Ayer fue una de las más bellas mañanas conciliares. En el lugar donde todos los días permanece expuesta la Sagrada Biblia, el santo Padre ha puesto una insigne reliquia: la cabeza del apóstol San Andrés, que Pablo VI enviará como regalo santo y altamente simbólico al patriarca de Constantinopla, Atenágoras. Cuando Grecia cayó en manos mahometanas, la reliquia fue llevada a Roma (12 de abril de 1462) y conservada en la tumba de San Pedro. Pío II pronunció entonces las palabras proféticas: “Sé bienvenida, oh sagrada reliquia! Refúgiate ante el cuerpo de tu hermano Pedro. Un día, terminado el exilio, te restituiremos a tu suelo glorioso” (ibíd.).

45 "Que todos sean uno, como tú en mí, oh Padre, y yo en ti; que sean ellos también una sola cosa en nosotros, para que el mundo crea que tú me has enviado" (Jn 17,21). 
Los trabajos del Concilio posibilitaron el contacto con los otros cristianos y dieron lugar a experiencias que antes no habían sido posibles: unos y otros vivieron juntos, oraron, conversaron, se escucharon, dialogaron, compartieron, se respetaron, se pidieron perdón, eliminaron prejuicios casi milenarios y tomaron conciencia de la responsabilidad de trabajar individual y colectivamente por la unión.

Y al final corroboraron que, al hacer parte de la gran familia de Cristo, seguían, amaban y servían al mismo Dios. Fueron claves, en este contexto, dos cuestiones: de lado y lado "depusieron las armas", "salieron de las trincheras", y comenzaron a dialogar y a conocerse, viendo más lo que nos une que lo que nos divide; también aprovecharon la oportunidad de conocer al otro, de ver la inmensa riqueza de la cual ese otro es depositario y lo que se puede aprender de él.

La Iglesia entera -como dijo Juan Pablo II- debe aprender a respirar de nuevo con sus dos pulmones, Oriente y Occidente.

Los observadores hicieron parte de un evento realmente histórico: el encuentro en la caridad entre las iglesias de Oriente y de Occidente, como conviene a los auténticos discípulos de Cristo, algo que antes del Concilio parecía casi imposible concebir.

Esta es una historia que debe continuar y a la cual cada uno debe contribuir según las propias posibilidades. La participación de estos hermanos en el Concilio nos hizo de nuevo, a todos, compañeros de camino en nuestra común historia eclesial. Con su participación hemos comenzado a escribir juntos, nuevamente, la historia de la Iglesia. Y si bien hay mucho que hacer todavía en campo ecuménico y este camino se vislumbra largo y complejo, es alentador saber que debemos y podemos hacerlo juntos en el nombre del Señor. La responsabilidad es de todos, y como bien precisó el papa Juan XXIII:

En el último día del juicio particular y del juicio universal será pedido a esta conciencia, no si ha hecho la unidad, sino si por ella ha orado, trabajado y sufrido; si se ha impuesto disciplina sabia y prudente, paciente y clarividente; y si ha dado vigor a los impulsos de la caridad. ${ }^{46}$

Para estimular el trabajo hacia la plena unidad, es necesario por parte de nosotros, en Occidente, conocer mejor el Oriente cristiano y hacerlo conocer a los otros ${ }^{47}$.

\footnotetext{
${ }^{46}$ Juan XXIII, “Radiomensaje navideño al mundo (22 de diciembre de 1962)”, 18.

${ }^{47}$ Congregación para la Educación Católica, "Carta circular En égard au développement tocante a los estudios sobre las iglesias orientales (6 de enero de 1987)". "En la elaboración de las propias decisiones y del estímulo que ha ofrecido a los teólogos y a los profesores católicos, el Concilio ha demostrado la profunda convicción de que un estudio sincero y profundo de la tradición de la Iglesia de Cristo no puede ignorar las tradiciones particulares de las diferentes iglesias cristianas, comprendidas aquellas orientales.
} 
Concluimos con tres textos del Concilio que invitan a aportar a la causa de la Union entre los cristianos y a profundizar en el conocimiento de los hermanos de las otras Comunidades eclesiales:

La preocupación por el restablecimiento de la unión atañe a la Iglesia entera, tanto a los fieles como a los pastores; y afecta a cada uno según su capacidad, ya sea en la vida cristiana diaria o en las investigaciones teológicas e históricas. Esta preocupación manifiesta ya de alguna manera la unión fraterna existente entre todos los cristianos, y conduce a la plena y perfecta unidad, según la benevolencia de Dios. ${ }^{48}$

Hay que conocer la mentalidad de los hermanos separados. Para esto se requiere necesariamente un estudio que debe realizarse según la verdad y con espíritu benévolo. Los católicos adecuadamente preparados deben adquirir un conocimiento de la doctrina e historia, de la vida espiritual y cultural, de la psicología religiosa y de la cultura propia de los hermanos. ${ }^{49}$

Teniendo en cuenta las condiciones de las diversas regiones, debe llevarse a los alumnos a un conocimiento más completo de las iglesias y comunidades eclesiales separadas de la Sede Apostólica Romana, para que puedan contribuir al restablecimiento de la unidad entre todos los cristianos, que hay que fomentar según las normas de este santo Sínodo. ${ }^{50}$

\section{Referencias}

Bea, Agostino. Ecumenismo nel Concilio: tappe pubbliche di un sorprendente camino. Milano: Bompiani, 1968.

Callovini, Carlo. "Gli acattolici al Concilio di Trento". Diario L'Osservatore Romano, Ciudad del Vaticano, 22 de marzo de 1962, p. 6.

Camara, Helder. Roma, due del mattino. Lettere dal Concilio Vaticano II. Milano: Edizioni San Paolo, 2008.

Caprile, Giovanni. (ed.). Il Concilio Vaticano II. Cronache del Concilio Vaticano II. Vol. I. L'annunzio e la prepazione, 1959-1962: Parte 1. 1959-1960. Roma: La Civiltà Cattolica, 1966. . (ed.). Il Concilio Vaticano II. Cronache del Concilio Vaticano II. Vol. II. Il primo periodo, 1962-1963. Roma: La Civiltà Cattolica, 1966.

[ibíd. 5]. En los seminarios y en las facultades teológicas sería además útil organizar cursos de base acerca de las iglesias orientales, sus principios teológicos, sus tradiciones litúrgicas y espirituales" (ibíd. 10).

${ }^{48}$ Concilio Vaticano II, "Decreto Unitatis redintegratio sobre el ecumenismo" 5.

${ }^{49}$ Ibíd. 9.

${ }^{50}$ Ídem, "Decreto Optatam totius sobre la formación sacerdotal” 16. 
Concilio Vaticano II. "Decreto Optatam totius, sobre la formación sacerdotal". AAS 58 (1966): 713-727.

. "Decreto Unitatis redintegratio sobre el ecumenismo". AAS 57 (1965): 90-112.

Congregación para la Educación Católica. "Carta circular En égard au développement tocante a los estudios sobre las iglesias orientales (6 de enero de 1987)". En Enchiridion Vaticanum 10. Documentos oficiales de la Santa Sede (1986-1987): 802-817. Bologna: Edizioni Dehoniane Bologna, 1989.

De Simone, Raffaele. "L'invito di Pio IV ad Ivan IV Zar di Russia per la partecipazione al Concilio di Trento". Unitas 1 (1962): 342-363.

Edelby, Neophytos. Il Vaticano II nel diario di un vescovo arabo. Milano: Edizioni San Paolo, 1996.

Ellis, Jane. La Chiesa Ortodossa Russa. Una storia contemporanea. Bologna: Edizioni Dehoniane Bologna, 1989.

Fesquet, Henri. Diario del Concilio. Tutto il Concilio giorno per giorno. Milano: Mursia, 1967.

Fouilloux, Étienne. "Des observateurs non catholiques". En Vatican II commence. Approches francophones por É. Fouilloux, 235-250. Leuven: Bibliotheek van de Faculteit der Godgeleerdheid, 1993.

Floridi, Alessio Ulisse. Mosca e il Vaticano. Milano: Edizioni R.C. La Casa di Matriona, 1976.

Guasco, Maurilio, Elio Guerriero: y Francesco Traniello. La Chiesa del Vaticano II (1958-1978). Parte 1. [Storia della Chiesa, Vol. 25]. Milano: Edizioni San Paolo, 1994.

Juan XXIII. "Radiomensaje navideño al mundo (22 de diciembre de 1962)". AAS 55 (1963): 18.

Juan Pablo II. "Carta encíclica Ut unum sint sobre el compromiso ecuménico". AAS 87 (1995): 921-982.

Nikodim. Uno scomodo ottimista Giovanni XXIII. Roma: Edizioni Paoline, 1983.

Osipova, Irina. Si el mundo os odia. Madrid: Encuentro, 1998.

Pospielovsy, Dimitry. The Russian Church under the Soviet Regime, 1917-1982. 2 vols. Crestwood (NY): St. Vladimir's Seminary Press, 1984.

Revista Ecclesia. "Los observadores hablan del Concilio. Algunas de sus declaraciones después de la primera sesión”. Ecclesia XXIII/1127 (1963): 23-24. 
Revista Oriente Cristiano. “Sección dedicada al Concilio Vaticano II”. Oriente cristiano 4 (1962): 24-25.

Revista Russia Cristiana. "Noticias sobre ecumenismo". Russia cristiana 76 (1966): 47.

Riccardi, Andrea. Il Vaticano e Mosca. 1940-1990. Roma-Bari: Editori Laterza, 1993.

Sacrosanctum Oecumenicum Concilium Vaticanum Secundum. "Index Observatorum Delegatorum ad Concilium Vaticanum II et Hospitum Secretariatus ad Unitatem Christianorum Fovendam”. En: Acta Synodalia. Acta et documenta series II (Praeparatoria). Vol. IV, Pars I. Città del Vaticano: Typis Polyglottis Vaticanis, 1986.

. "Observateurs-délégues et hôtes du Secrétariat pour L'Unité des Chrétiens au deuxième Concile Oecumenique du Vatican II". Città del Vaticano: Typis Polyglottis Vaticanis, 1965.

Sacrosanctum Oecumenicum Concilium Vaticanum Secundum-Ordo Concilii Oecumenici Vaticanis Secundi Celebrandi. "Textus Emendatus et Promulgatus". En: Acta et documenta series II (Praeparatoria). Vol. IV, Pars I. Città del Vaticano, Typis Polyglottis Vaticanis, 1962.

Tamborra, Angelo. Chiesa Cattolica e Ortodossia russa. Due secoli di confronto e dialogo. Dalla Santa Alleanza ai nostri giorni. Torino: Edizioni Paoline, 1992.

Wenger, Antoine. Le Concile Vatican II. Croniques des sessiones du Concile. Vol. 1. Cronique de la Ire session. Paris: Éditions du Centurion, 1963.

Zizola, Giancarlo. Giovanni XXIII. La fede e la politica. Roma-Bari: Editori Laterza, 1988.

. L’utopia di papa Giovanni. Assisi: Citadella Editrice, 2000. 